
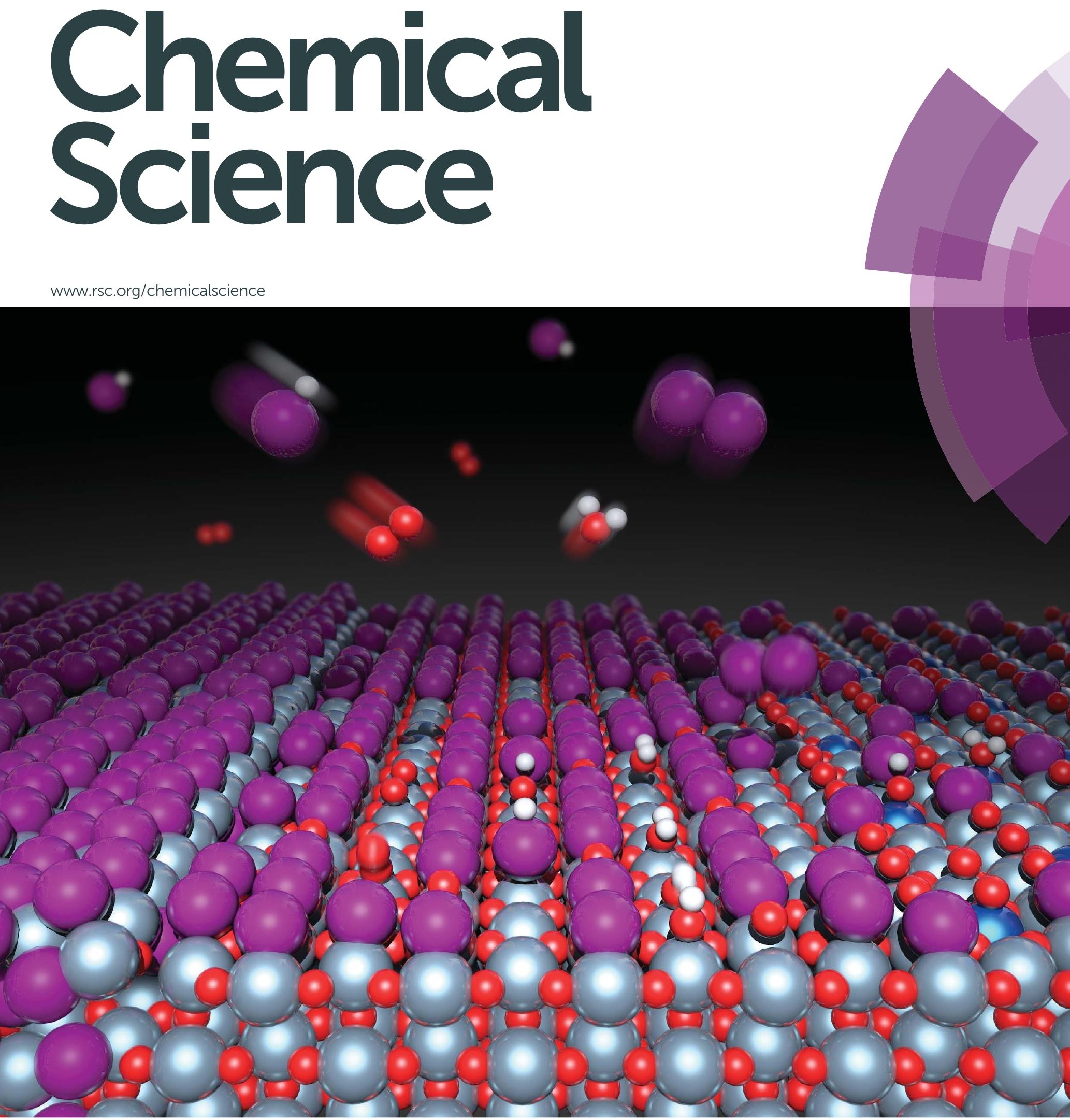

ISSN 2041-6539

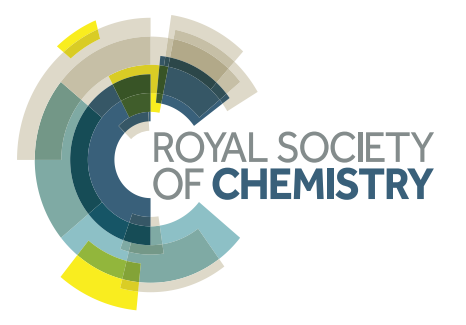

\section{EDGE ARTICLE}

Núria López, Detre Teschner, Javier Pérez-Ramírez et al.

Interplay between surface chemistry and performance of rutile-type

catalysts for halogen production

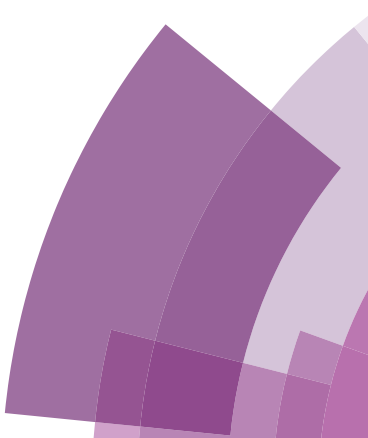




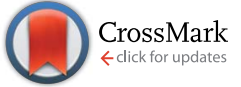

Cite this: Chem. Sci., 2016, 7, 2996

\title{
Interplay between surface chemistry and performance of rutile-type catalysts for halogen production $\dagger$
}

\author{
Maximilian Moser, ${ }^{a}$ Vladimir Paunović, ${ }^{a}$ Zhen Guo, ${ }^{a}$ László Szentmiklósi, ${ }^{b}$ \\ Miguel G. Hevia, ${ }^{c}$ Michael Higham, ${ }^{c}$ Núria López, ${ }^{\star c}$ Detre Teschner ${ }^{\star d}$ \\ and Javier Pérez-Ramírez ${ }^{\star a}$
}

Catalytic $\mathrm{HBr}$ oxidation is an integral step in the bromine-mediated functionalisation of alkanes to valuable chemicals. This study establishes the relationships between the mechanism of $\mathrm{HBr}$ oxidation over rutiletype oxides $\left(\mathrm{RuO}_{2}, \mathrm{IrO}_{2}, \mathrm{TiO}_{2}\right)$ and their apparent catalytic performance. Comparison with the wellstudied $\mathrm{HCl}$ oxidation revealed distinct differences in surface chemistry between $\mathrm{HBr}$ and $\mathrm{HCl}$ oxidation that impact the stability and activity of the catalysts. The kinetic fingerprints of both oxidation reactions over the three rutile-type oxides investigated are compared using temporal analysis of products, which substantiates the energy profiles derived from density functional theory. The quantitative determination of the halogen uptake under operando conditions using prompt gamma activation analysis demonstrates that $\mathrm{RuO}_{2}$ suffers from extensive subsurface bromination upon contact with hydrogen bromide, particularly at low temperature and low $\mathrm{O}_{2}: \mathrm{HBr}$ ratios, which negatively affects the stability of the catalyst. $\mathrm{TiO}_{2}$ exhibits intrinsically low halogen coverage (30-50\%) under all the conditions investigated, due to its unique defect-driven mechanism that renders it active and stable for $\mathrm{Br}_{2}$ production. On the contrary, for $\mathrm{HCl}$ oxidation $\mathrm{TiO}_{2}$ is inactive, and the chlorination of the highly active $\mathrm{RuO}_{2}$ is limited to the surface. Differences in the extent of surface halogenation of the materials were also confirmed by high-resolution transmission electron microscopy and explained by the DFT calculations. These insights into the molecular-level processes taking place under working conditions pave the way for the design of

the next generation catalysts for bromine production.

Received 8th November 2015 Accepted 27th January 2016

DOI: $10.1039 / c 5 s c 04247 j$

www.rsc.org/chemicalscience

\section{Introduction}

The surface chemistry of metal oxides that exhibit a rutile structure is rich and complex. ${ }^{1}$ Their dense lattice structure renders these materials stable against harsh reaction conditions and makes them an attractive option for applications in heterogeneous, electro-, and photo-catalysis. ${ }^{1,2}$ Recently, the

${ }^{a}$ Institute for Chemical and Bioengineering, Department of Chemistry and Applied Biosciences, ETH Zurich, Vladimir-Prelog-Weg 1, 8093 Zurich, Switzerland. E-mail: jpr@chem.ethz.ch

${ }^{b}$ Centre for Energy Research, Hungarian Academy of Sciences, Konkoly-Thege Miklós Street 29-33, 1121 Budapest, Hungary

'Institute of Chemical Research of Catalonia, ICIQ, Barcelona Institute of Science and Technology, BIST, Av. Països Catalans 16, 43007 Tarragona, Spain. E-mail:nlopez@ iciq.es

${ }^{d}$ Fritz-Haber-Institute of the Max Planck Society, Faradayweg 4-6, 14195 Berlin, Germany.E-mail: teschner@fhi-berlin.mpg.de

$\dagger$ Electronic supplementary information (ESI) available: Additional computational details, additional HRTEM analysis, energy values, illustrations, and contour plots of the $a b$ initio thermodynamics, transient responses of TAP experiments, reaction profile of the HX oxidation half cycle, and rate of halogen formation versus the halogen coverage. See DOI: $10.1039 / \mathrm{c} 5 \mathrm{sc} 04247 \mathrm{j}$ implementation of $\mathrm{RuO}_{2}$-based catalysts for the recovery of chlorine via the oxidation of $\mathrm{HCl}$, a copious by-product of polyurethane and polycarbonate production, stimulated multiple studies employing interdisciplinary methods. ${ }^{1,3}$ It was demonstrated that the stability of $\mathrm{RuO}_{2}$ against bulk chlorination originates from a self-limiting mechanism that confines the chlorination to the surface, while its low temperature activity is linked to the small energetic barrier for the evolution of chlorine. ${ }^{4}$ Operando studies on $\mathrm{RuO}_{2}$ showed that the activity is related to the extent of surface chlorination and can be controlled through variation of temperature and oxygen partial pressure. $^{5}$

Rutile-type catalysts were also studied for the gas-phase oxidation of $\mathrm{HBr}$ to $\mathrm{Br}_{2}$, a crucial step in closing the bromine cycle in emerging bromine-mediated alkane functionalisation processes. ${ }^{6}$ It was found that $\mathrm{RuO}_{2}{ }^{-}$and $\mathrm{IrO}_{2}$-based systems catalyse $\mathrm{HBr}$ oxidation at much lower temperatures than $\mathrm{HCl}$ oxidation, due to the lower energy barrier of bromine evolution compared to that of chlorine evolution. ${ }^{6 d}$ Further studies resulted in the discovery of $\mathrm{TiO}_{2}$ as an active catalyst for $\mathrm{HBr}$ oxidation, despite its inertness in $\mathrm{HCl}$ oxidation. ${ }^{7}$ Molecular modelling studies proposed that a self-doping mechanism with 
bromine enables the adsorption and activation of molecular oxygen on $\mathrm{TiO}_{2}{ }^{7}$ These results underlined that the mechanism of $\mathrm{HBr}$ oxidation is more multifarious than that of $\mathrm{HCl}$ oxidation on rutile surfaces. However, there is a lack of systematic studies that enable one to rationalise the relationship between the state of the surface and the apparent catalytic performance of different rutile-type catalysts in $\mathrm{HBr}$ oxidation. A comprehensive mechanistic picture can be developed through a multidisciplinary approach combining theoretical calculations with ex situ and operando methods.

Herein, we undertake a detailed study of the surface chemistry of rutile-type catalysts, i.e. $\mathrm{RuO}_{2}, \mathrm{IrO}_{2}$, and $\mathrm{TiO}_{2}$, in $\mathrm{HBr}$ oxidation, including a direct comparison to $\mathrm{HCl}$ oxidation. Advanced characterisation techniques provide an in-depth perspective on the catalytic hydrogen halide oxidation that goes beyond the experimental limitations of previous studies on $\mathrm{HBr}$ oxidation. Analysis of microscopic imaging and energy profiles calculated from Density Functional Theory rationalise the interactions of the gaseous environment with the catalysts. The dynamics of product formation are deduced from temporal analysis of products. These are combined with operando prompt gamma activation analysis experiments under steady-state conditions, enabling determination of the halogen surface coverage. Merging these results, we discuss the impact of surface halogenation by hydrogen halides on the structural stability of the rutile materials and the mechanistic fingerprints of hydrogen halide oxidation over these catalysts.

\section{Experimental}

\section{Catalyst preparation}

The as-received $\mathrm{RuO}_{2}\left(11 \mathrm{~m}^{2} \mathrm{~g}^{-1}\right.$, Aldrich, 99.5\%) and $\mathrm{TiO}_{2}$ $\left(20 \mathrm{~m}^{2} \mathrm{~g}^{-1}\right.$, Aldrich, rutile nanopowder, $\left.99.5 \%\right)$ powders were calcined at 723 and $823 \mathrm{~K}$, respectively, using a ramp of $5 \mathrm{~K}$ $\min ^{-1}$ and a holding time of $5 \mathrm{~h}$. $\operatorname{IrO}_{2}\left(9 \mathrm{~m}^{2} \mathrm{~g}^{-1}\right)$ was prepared by calcination of anhydrous $\operatorname{IrCl}_{3}(\mathrm{ABCR}, 99.9 \%)$ at $823 \mathrm{~K}$ for $5 \mathrm{~h}$ using a heating rate of $5 \mathrm{~K} \mathrm{~min}^{-1}$.

\section{High-resolution transmission microscopy}

High-resolution transmission electron microscopy (HRTEM) was undertaken on either a FEI Tecnai F30 microscope operated at $300 \mathrm{kV}$ or a FEI Talos microscope operated at $200 \mathrm{kV}$. Elemental mapping using energy-dispersive X-ray spectroscopy (EDXS) was carried out in STEM-mode with 4 X-ray detectors (Bruker) attached to the Talos microscope. Prior to microscopic analysis, the solids were dispersed in ethanol; a few droplets of the suspension were poured onto a holey carbon-coated copper grid and dried completely.

\section{Computational details}

Density functional theory (DFT), as implemented in the Vienna ab initio simulation package (VASP) version 5.3.3, was applied to slabs representing the rutile (110) facet, for both $\mathrm{RuO}_{2}$ and $\mathrm{TiO}_{2} \cdot{ }^{8}$ For all rutile-type catalysts, the (110) surface represents the largest contribution to the surface in the Wulff construction of the nanoparticles. For example, $\mathrm{RuO}_{2}$ exhibits $43 \%$ of the
(110) facet and a complementary $42 \%$ of the (101) facet. ${ }^{5 b}$ For calculations involving $\mathrm{RuO}_{2}(110)$, a $p(2 \times 1)$ supercell was employed, with a $k$-point sampling of $4 \times 4 \times 1$, using the scheme of Monkhorst and Pack. ${ }^{9}$ For calculations involving $\mathrm{TiO}_{2}(110)$, the chosen slab corresponds to a $p(2 \times 2)$ supercell, with a $k$-point sampling of $4 \times 2 \times 1$. In both cases, slabs consisting of five layers were interleaved by a $15 \AA$ vacuum. The top two layers of the slabs were optimised, while the remaining bottom three were fixed. Forces were converged to within 0.015 $\mathrm{eV} \AA^{-1}$. In order to eliminate the spurious electrostatic interactions associated with asymmetric relaxation of the slab, a dipole correction was applied to the vacuum. The exchangecorrelation functional $\mathrm{PBE},{ }^{10}$ as well as $\mathrm{PBE}+\mathrm{U}^{11}$ for $\mathrm{TiO}_{2}$, was employed, with $U_{\text {eff }}=4.5 \mathrm{eV}$ for Ti. Inner electrons were replaced with PAW, ${ }^{12}$ and the valance states were expanded in plane-waves with a cut-off energy of $450 \mathrm{eV}$. Spin-polarised calculations were performed as necessary. Transition states were identified by CI-NEB. ${ }^{13} \mathrm{Ab}$ initio thermodynamics calculations were performed using lowest energy surface configurations to determine the surface composition under typical experimental conditions as a function of the partial pressures, $p(\mathrm{HX}), p\left(\mathrm{H}_{2} \mathrm{O}\right)$, and $p\left(\mathrm{X}_{2}\right) ;(\mathrm{X}=\mathrm{Cl}, \mathrm{Br})$. The experimental gasphase thermodynamic data from the NIST reference tables were utilised in conjunction with the DFT results for the relevant molecular species (viz. $\mathrm{HCl}, \mathrm{HBr}, \mathrm{Cl}_{2}, \mathrm{Br}_{2}$, and $\mathrm{H}_{2} \mathrm{O}$ ). ${ }^{14}$ The simulations were conducted under various partial pressures and temperatures for $\mathrm{RuO}_{2}$ and $\mathrm{TiO}_{2}$ with different degrees of halogenation. Additional computational details with regard to halogen substitution in the rutile structures are provided in the ESI. $\dagger$ Note that the results of the ab initio thermodynamics indicate the most stable configuration of the material as a function of external temperatures and pressures. Thus, the lowest energy halide distributions are identified, but not the process (kinetics or mechanism) of how subsurface halide uptake takes place.

\section{Temporal analysis of products (TAP)}

Transient mechanistic studies of $\mathrm{HBr}$ and $\mathrm{HCl}$ oxidation over $\mathrm{RuO}_{2}, \mathrm{IrO}_{2}$, and $\mathrm{TiO}_{2}$ were carried out in a TAP-2 reactor. ${ }^{15}$ The samples $(10 \mathrm{mg}$, particle size $=0.2-0.4 \mathrm{~mm})$ were loaded in the isothermal (central) zone of a stainless steel micro-reactor (4.6 $\mathrm{mm}$ internal diameter) between two layers of quartz particles of size $0.125-0.2 \mathrm{~mm}$. The thickness of the catalyst zone (1-2 mm) was very small compared with the overall bed length $(37 \mathrm{~mm})$. This configuration, referred to as a thin-zone reactor, is characterised by negligible gas concentration gradients across the catalyst bed. ${ }^{15 b}$ The samples were pre-treated in a flow of $20 \mathrm{~cm}^{3} \mathrm{STP} \mathrm{min}^{-1} \mathrm{O}_{2}$ at $623 \mathrm{~K}$ and 1 bar for $1 \mathrm{~h}$, followed by evacuation of the reactor to $10^{-10}$ bar. The following pulse experiments were carried out in high vacuum at 523, 573, and $623 \mathrm{~K}$ for $\mathrm{HBr}$ and at $623 \mathrm{~K}$ for $\mathrm{HCl}$ oxidation, using a pulse size of $c a .10^{16}$ molecules: (a) individual pulsing of either $\mathrm{O}_{2}: \mathrm{He}=$ $8: 1$ or $\mathrm{HX}: \mathrm{Ar}=16: 1(\mathrm{X}=\mathrm{Cl}, \mathrm{Br})$; (b) simultaneous pulsing of $\mathrm{O}_{2}: \mathrm{He}=8: 1$ and $\mathrm{HX}: \mathrm{Ar}=16: 1$; and (c) pump-probe pulsing of $\mathrm{O}_{2}: \mathrm{He}=8: 1$ and $\mathrm{HX}: \mathrm{Ar}=4: 1$. The latter is also referred to as sequential pulsing, where the pulses of the two gas 
mixtures are separated by a time delay $(\Delta t)$. The pulses were separated by 0.25 and $1 \mathrm{~s}$ for $\mathrm{O}_{2}$ : He (pump pulse) and $\mathrm{HX}: \mathrm{Ar}$ (probe pulse). In the case of $\mathrm{HX}: \mathrm{Ar}$ (pump pulse) and $\mathrm{O}_{2}: \mathrm{He}$ (probe pulse), the delays were 2 and $8 \mathrm{~s}$. The pump and probe pulses were repeated cyclically, keeping a constant time interval of $8 \mathrm{~s}$ between the probe pulse in one cycle and the pump pulse in the following cycle in all cases.

In the experiments, Ar (Linde, purity 5.0), He (Air Products, purity 5.2), $\mathrm{O}_{2}$ (Air Products, purity 5.2), $\mathrm{HBr}$ (Linde, purity 4.5), and $\mathrm{HCl}$ (Linde, purity 2.8) were used. A quadrupole mass spectrometer (RGA 300, Stanford Research Systems) monitored the transient responses at the reactor outlet of the following atomic mass units (AMUs): $160\left(\mathrm{Br}_{2}\right), 80(\mathrm{HBr}), 70\left(\mathrm{Cl}_{2}\right), 40(\mathrm{Ar})$, $36(\mathrm{HCl}), 32\left(\mathrm{O}_{2}\right), 18\left(\mathrm{H}_{2} \mathrm{O}\right)$, and $4(\mathrm{He})$. The responses displayed correspond to an average of 20 pulses per AMU to improve the signal-to-noise ratio. Prior to that, it was verified that the responses were stable; that is, with invariable intensity and shape during at least 40 consecutive pulses.

\section{Operando prompt gamma activation analysis}

The $\mathrm{Br}$ and $\mathrm{Cl}$ uptake on the rutile-type catalysts during $\mathrm{HBr}$ and $\mathrm{HCl}$ oxidation was determined using operando prompt gamma activation analysis (PGAA) using the cold neutron beam at the Budapest Neutron Centre. The technique was successfully used to study the surface chlorination of Deacon catalysts $^{5,16}$ and is based on neutron capture by the atomic cores in the sample and the subsequent detection of elementspecific gamma rays emitted during de-excitation of the nuclei. The gas-phase oxidation of hydrogen halides was studied in a quartz fixed-bed micro-reactor $(8 \mathrm{~mm}$ internal diameter) at ambient pressure and in the temperature range of 413-713 K. The reactor was loaded with $0.5 \mathrm{~g}$ of $\mathrm{RuO}_{2}$ or $0.23 \mathrm{~g}$ of $\mathrm{TiO}_{2}$ catalyst (particle size $=0.4-0.6 \mathrm{~mm}$ ) and was placed inside a furnace in the path of the neutron beam. A total volumetric flow of $250 \mathrm{~cm}^{3}$ STP $\mathrm{min}^{-1}$ consisting of $10 \mathrm{vol} \%$ $\mathrm{HBr}$ or $\mathrm{HCl}$ (Air Liquide, anhydrous) and 0-90 vol\% $\mathrm{O}_{2}$ (Linde, purity 4.5 ) balanced in $\mathrm{N}_{2}$ (Linde, purity 5.0) was continuously fed into the reactor. Furthermore, 0-4 vol\% $\mathrm{Br}_{2}$ (Acros, 99.8\%) was added to the gas feed by passing part of the $\mathrm{N}_{2}$ flow through a saturator filled with liquid $\mathrm{Br}_{2}$ under STP conditions. The halogen formation was quantified by iodometric titration using a Mettler Toledo G20 Compact Titrator, as detailed elsewhere. ${ }^{4 d}$ The rate of halogen formation was expressed as moles of halogen produced per gram of catalyst and unit of time. The cold neutrons were guided to the experimental station by curved supermirror neutron guides. A Compton-suppressed high-purity germanium (HPGe) crystal detects the prompt gamma photons emitted by the catalyst bed. $\mathrm{Br}, \mathrm{Cl}, \mathrm{Ru}$, and $\mathrm{Ti}$ were determined from the characteristic peak areas. The surface coverage was calculated as the amount of halogen per surface site, taking into account the surface area of the catalysts and the density of sites on the (110) and (101) facets, weighted by their relative occurrence. ${ }^{5 a, 17}$ The gas-phase signals of $\mathrm{HBr}, \mathrm{Br}_{2}, \mathrm{HCl}$, and $\mathrm{Cl}_{2}$ were subtracted; thus, all reported values correspond to the solid catalyst only.

\section{Results and discussion}

\section{Halogenation of rutile structures}

The depicted nano-particles of $\mathrm{RuO}_{2}$ and $\mathrm{TiO}_{2}$ are $c a .20 \mathrm{~nm}$ and $50 \mathrm{~nm}$ in size, respectively, and exhibit sharp edges with clearly visible fringes, providing a high degree of crystallinity as shown by HRTEM (Fig. 1). After treatment in both $\mathrm{HBr}$ and $\mathrm{HCl}$ for $3 \mathrm{~h}$ (i.e. $\mathrm{O}_{2}: \mathrm{HX}=0$ ), both $\mathrm{RuO}_{2}$ and $\mathrm{TiO}_{2}$ particles retained their size, while the $\mathrm{RuO}_{2}$ surfaces exhibited significant amorphisation compared to $\mathrm{TiO}_{2}$. The evaluation of the $\mathrm{RuO}_{2}$ crystals showed that the amorphised layer is thicker after treatment in $\mathrm{HBr}$ compared to $\mathrm{HCl}$ (Fig. 1 and $\mathrm{S} 1 \dagger$ ). Analysis of the HBr-treated samples with EDXS corroborated this observation, detecting a significant concentration of bromine along the particle edges (Fig. 1, middle). The $\mathrm{TiO}_{2}$ surfaces were virtually unaffected by the $\mathrm{HBr}$ and $\mathrm{HCl}$ treatment. The EDXS mapping of $\mathrm{TiO}_{2}$ did not detect significant traces of chlorine, and only small amounts of bromine were observed (Fig. 1 and $\mathrm{S} 2 \dagger)$. These results are further supported by the measured halogen uptake under the reaction conditions, which indicates a four times higher bromine uptake on $\mathrm{RuO}_{2}$ compared to chlorine and comparably low halogen uptake on $\mathrm{TiO}_{2}$ (vide infra).

In previous studies, it has been observed that rutile-type catalysts used in heterogeneous catalysis are affected by the chemical environment in which the reaction takes place. Theoretical investigations of the active phase can be conducted at different levels of complexity. For instance, bulk stability against complete halogenation (i.e. where bulk $\mathrm{MO}_{2}$ is replaced by $\mathrm{MX}_{n}$ ) and the possibility of rutile degradation via the formation of volatile species $\left(\mathrm{TiCl}_{4}\right.$ formation would be an example) could also be considered. However, to address the formation of mixed phases it is more illustrative to conduct simulations of the substitution of surface and subsurface oxygen atoms by halogen atoms in the lattice of $\mathrm{RuO}_{2}$. The theoretical replacement energies reported were calculated according to the equation $\mathrm{RuO}_{2}+2 n \mathrm{HX} \rightarrow \mathrm{RuO}_{2-n} @ \mathrm{X}_{n}+n \mathrm{H}_{2} \mathrm{O}$ $+n / 2 \mathrm{X}_{2}$, where $n$ is the number of oxygen atoms replaced and $\mathrm{X}$ refers to either $\mathrm{Br}$ or $\mathrm{Cl}$. Lattice oxygen enters the gas phase in the form of water. The energies for $\mathrm{RuO}_{2}$ bromination are most exothermic for configurations corresponding to the substitution of two $\mathrm{O}$ atoms $\left(\Delta E_{\mathrm{r}}=-1.97 \mathrm{eV}\right.$, Fig. S3, 2A $\left.\dagger\right)$, and remain significantly exothermic for up to four $\mathrm{Br}$ atoms $\left(\Delta E_{\mathrm{r}}>-1 \mathrm{eV}\right.$, Fig. S3, 4B $\dagger$ ). Upon addition of the first subsurface $\mathrm{Br}$ atom, the bromination becomes less exothermic $\left(\Delta E_{\mathrm{r}}=-0.50 \mathrm{eV}\right.$, Fig. S3, $5 \mathrm{C} \dagger)$, and eventually it becomes slightly endothermic after the addition of a further $\mathrm{Br}$ atom $\left(\Delta E_{\mathrm{r}}=0.30 \mathrm{eV}\right.$, Fig. $\left.\mathrm{S} 3,6 \mathrm{H} \dagger\right)$. Notably, the incorporation of four or more $\mathrm{Br}$ atoms into the lattice already leads to a considerable degree of structural rearrangement (Fig. S4, 4B and $\mathrm{F}_{\dagger}^{\dagger}$ ). The surface $\mathrm{Br}$ atoms relax such that they form a hexagonal arrangement (Fig. S5†). The high $\mathrm{Br}$ density of these structures represents a change in the geometry that would appear as amorphisation in the experiments (Fig. 1, and S1 $\dagger$ ). Furthermore, considering factors unaccounted for by the above methodology, such as configurational entropy or other surface orientations, extensive 

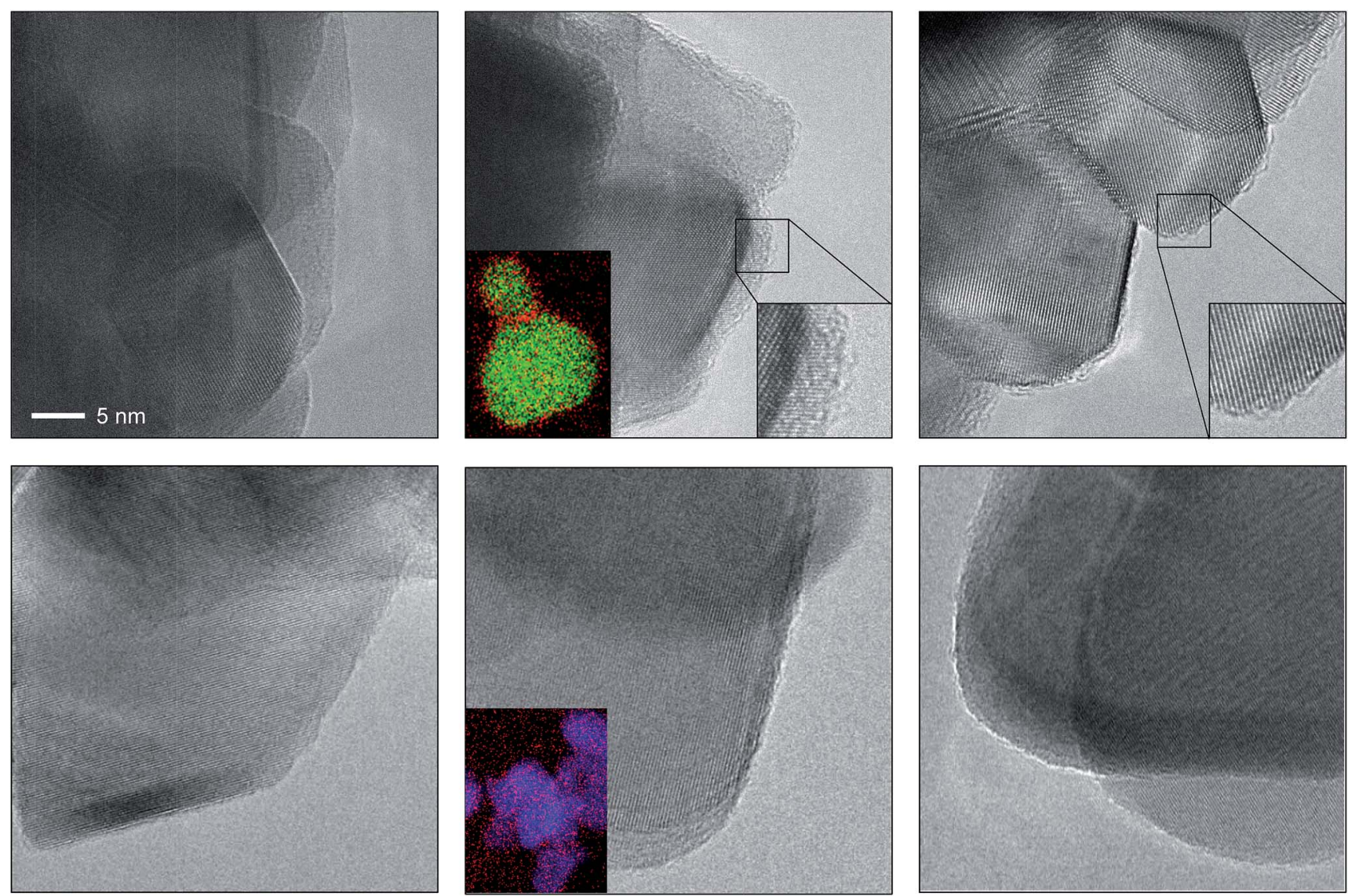

Fig. $1 \mathrm{HRTEM}$ images of $\mathrm{RuO}_{2}$ (top) and $\mathrm{TiO}_{2}$ (bottom) showing the as-prepared materials (left), and the materials after treatment in $\mathrm{HBr}$ at $393 \mathrm{~K}$ (centre) and HCl at $543 \mathrm{~K}$ (right). The scale bar in the top left image applies to all images. The bottom left insets in the centre micrographs depict the averaged elemental mapping of the $\mathrm{RuO}_{2}$ and $\mathrm{TiO}_{2}$ particles using EDXS, with Ru shown in green, Ti shown in blue and $\mathrm{Br}$ shown in red. The bottom right insets in the top centre and right micrographs show magnified images of the amorphised particle edges. Additional micrographs of $\mathrm{RuO}_{2}$ and $\mathrm{TiO}_{2}$ (Fig. S1 and $\mathrm{S} 2 \dagger$ ) and structural models (Fig. S4 and S5 $\dagger$ ) of brominated $\mathrm{RuO}_{2}$ are provided in the ESI. $\dagger$

subsurface bromination is well within the bounds of possibility. ${ }^{4 c}$ The present calculations only aim at establishing the lowest energy configurations and do not provide any indication as to how the bromination occurs. For $\mathrm{RuO}_{2}$ chlorination, the process is only exothermic for up to two $\mathrm{Cl}$ atoms incorporated into the surface $\left(\Delta E_{\mathrm{r}}=-0.93 \mathrm{eV}\right.$, Fig. S3, 2A $\left.\dagger\right)$, with subsequent $\mathrm{Cl}$ addition being endothermic (Fig. S3b, 3A $\dagger$ ). While incorporation of up to four $\mathrm{Cl}$ atoms is moderately endothermic $\left(\Delta E_{\mathrm{r}}\right.$ $=0.71 \mathrm{eV}$, Fig. S3, $4 \mathrm{~B} \dagger$ ), subsequent chlorination of the subsurface layers is considerably more so, reaching $\Delta E_{\mathrm{r}}=1.81$ $\mathrm{eV}$ and $3.21 \mathrm{eV}$ for five and six $\mathrm{Cl}$ atoms, respectively (Fig. S3, $5 \mathrm{C} \dagger$ and $6 \mathrm{H} \dagger)$.

$A b$ initio thermodynamic studies were performed to identify which halogenated structures would be stable under the treatment conditions, i.e. variable $\mathrm{HX}$ and low product partial pressures (Fig. 2). $\$$ The results show that the surface composition consists of between two and four $\mathrm{Br}$ atoms or two $\mathrm{Cl}$ atoms per $(2 \times 1)$ supercell between $p(\mathrm{HX})=10^{-2}$ and 100 bar.§ Higher $p(\mathrm{HX})$ favours more extensively halogenated structures, while the free energy for substitution of $\mathrm{Br}$ atoms remains more exothermic than that for $\mathrm{Cl}$ atoms for all partial pressures in the range considered. This indicates that bromination is stronger under comparable conditions, as observed in the microscopic analysis. The impact of $p\left(\mathrm{H}_{2} \mathrm{O}\right)$ and $p\left(\mathrm{X}_{2}\right)$ on the $\mathrm{RuO}_{2}$ surface composition is less pronounced (Fig. S6 and S7 $\dagger$ ), with the surface structure showing considerably less variation over the same pressure range as compared to $p(\mathrm{HX})$.

The calculations for $\mathrm{TiO}_{2}$, on the other hand, show that $\mathrm{Br}$ uptake is endothermic for incorporation of both one and two $\mathrm{Br}$ atoms, with $\Delta E_{\mathrm{r}}=0.43 \mathrm{eV}$ and $1.33 \mathrm{eV}$, respectively (Fig. S8, 1A and $2 \mathrm{~B} \dagger$ ). The lowest energy configuration for two $\mathrm{Br}$ atoms had them both occupying bridging sites in diagonal fashion, as this would result in minimal repulsion between them (Fig. S8a, $2 \mathrm{~B} \dagger$ ). Our $a b$ initio thermodynamics suggest that under typical experimental conditions, i.e. low $p\left(\mathrm{H}_{2} \mathrm{O}\right)$ and $p\left(\mathrm{Br}_{2}\right)$, as well as high $p(\mathrm{HBr})$, the $\mathrm{Br}$ uptake is limited, with a maximum of one $\mathrm{Br}$ atom per $(2 \times 2)$ surface cell. Furthermore, the free energy of substitution of a $\mathrm{Br}$ atom into $\mathrm{TiO}_{2}$ is much lower than those of $\mathrm{RuO}_{2}$ chlorination and bromination (Fig. 2). The product partial pressures have a very limited impact on the surface bromination, thus indicating that the HX partial pressure is the dominant factor in determining the halogenation of rutile-type structures. 

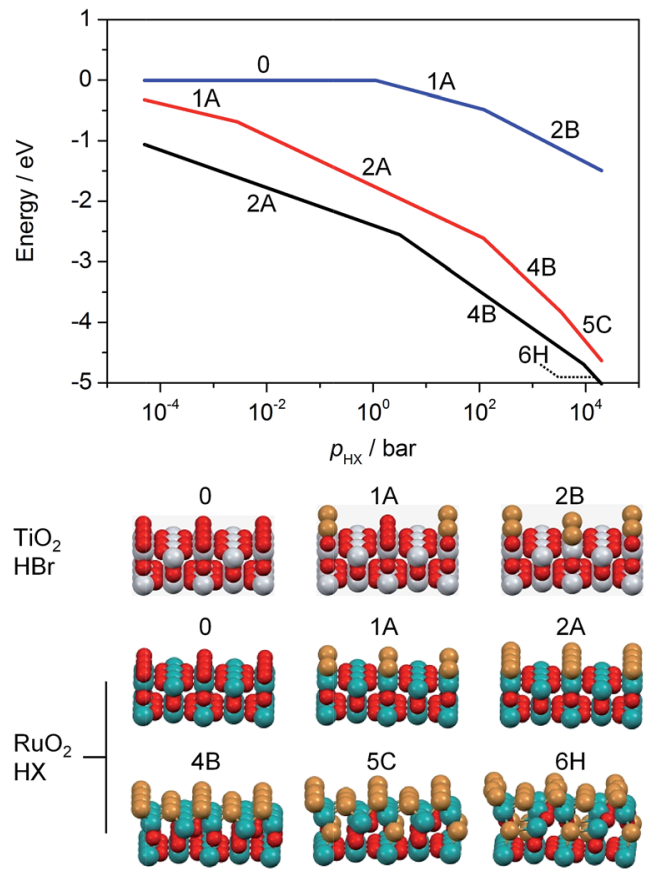

Fig. 2 Free energy of substitution versus the partial pressure of the hydrogen halide for the bromination of $\mathrm{TiO}_{2}$ (blue) and $\mathrm{RuO}_{2}$ (black), as well as for the chlorination of $\mathrm{RuO}_{2}$ (red). The partial pressures of $\mathrm{X}_{2}$ and $\mathrm{H}_{2} \mathrm{O}$ were fixed at $10^{-4}$ bar. The temperature was set to $573 \mathrm{~K}$ $\left(\mathrm{TiO}_{2}\right)$ and $393 \mathrm{~K}\left(\mathrm{RuO}_{2}\right)$ for bromination and $523 \mathrm{~K}\left(\mathrm{RuO}_{2}\right)$ for chlorination. The labels in the plot correspond to the structures shown below, which exhibit the lowest free energy under the simulated conditions. These depict the substitution of $\mathrm{Cl}$ or $\mathrm{Br}$ atoms into the surface and subsurface layers. Colour code: Ti (grey), Ru (green), O (red), and $\mathrm{Cl}$ or $\mathrm{Br}$ (brown).

\section{Mechanistic studies}

The analysis of the reaction mechanism of $\mathrm{HBr}$ and $\mathrm{HCl}$ oxidation was conducted by combining pulse experiments in a TAP-2 reactor with DFT calculations, which allowed us to study the reactant and product evolution corroborated by theoretical simulations. In order to compare the interactions of $\mathrm{HBr}$ and $\mathrm{HCl}$ with the catalysts, individual pulses of either $\mathrm{HBr}$ or $\mathrm{HCl}$ molecules were applied to the rutile catalysts (Fig. 3). When comparing the normalised peak responses of $\mathrm{HCl}$ and $\mathrm{HBr}$, we observe that the $\mathrm{HBr}$ peaks are significantly delayed by $0.44 \mathrm{~s}$ $\left(\mathrm{RuO}_{2}\right), 0.82 \mathrm{~s}\left(\mathrm{TiO}_{2}\right)$, and $0.17 \mathrm{~s}\left(\mathrm{IrO}_{2}\right)$, compared to the $\mathrm{HCl}$ peaks. This indicates that $\mathrm{HBr}$ interacts more strongly with the surface than $\mathrm{HCl}$, which is in line with the HRTEM and DFT results, and the calculated dissociative adsorption energy for $\mathrm{RuO}_{2}(110)$, which is $-2.33 \mathrm{eV}$ for $\mathrm{HBr}$ compared to $-2.09 \mathrm{eV}$ for $\mathrm{HCl}$ on the clean surface. Comparing the catalysts, the order of the $\mathrm{HBr}$ peak maxima is as follows: $\mathrm{RuO}_{2}<\mathrm{IrO}_{2}<\mathrm{TiO}_{2}$ at 523, 573 , and $623 \mathrm{~K}$ (Fig. S9†). The peak position is affected by changing the temperature, and the peak is significantly delayed at higher temperature. This indicates a sizable activation barrier for the overall process during the TAP experiment, which is likely due to underlying surface/subsurface processes (vide supra). Furthermore, a difference between the $\mathrm{HBr}$ pulses for individual $\mathrm{HBr}$ and simultaneous $\mathrm{HBr}+\mathrm{O}_{2}$ pulsing is observed

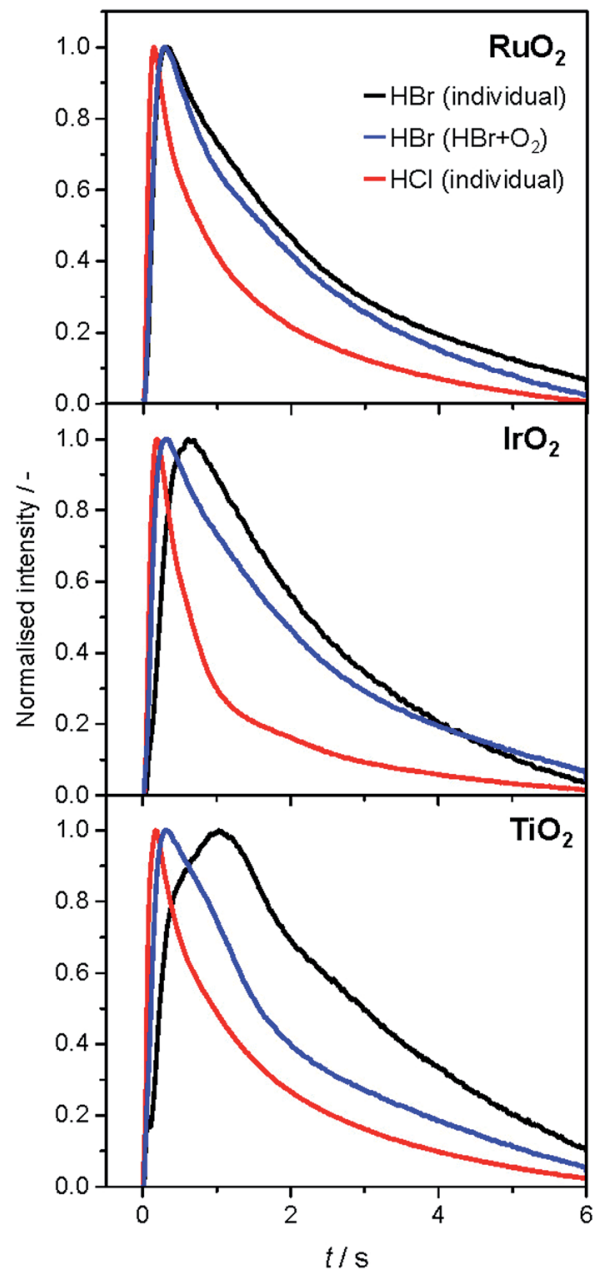

Fig. 3 Normalised transient responses of $\mathrm{HBr}$ and $\mathrm{HCl}$ after individual $\left(\mathrm{HBr}\right.$, black; $\mathrm{HCl}$, red), and simultaneous $\left(\mathrm{HBr}+\mathrm{O}_{2}\right.$, blue) pulse experiments at $623 \mathrm{~K}$.

for $\mathrm{IrO}_{2}(0.31 \mathrm{~s})$, and $\mathrm{TiO}_{2}$ (0.67 s) (Fig. 3). The shift could be due to the reaction of $\mathrm{HX}$ and $\mathrm{O}_{2}$ to form $\mathrm{X}_{2}$ and water, in which the reactants are consumed (Fig. 3 and $\mathrm{S} 10^{\dagger}$ ), leading to a reduction of the integrated peak area. This leads to a shift of the HX peak maximum to shorter times and less tailing of the signal in comparison to the individual pulsed reactant signal, assuming that the pulse size of the reactant was about the same in both individual and simultaneous pulsing experiments. ${ }^{4 d, 18}$ For $\mathrm{RuO}_{2}$, a difference in tailing is observed, but no clear shift of the peak position is visible, which might indicate that the interaction between $\mathrm{RuO}_{2}$ and $\mathrm{HBr}$ is not significantly affected by the simultaneously pulsed oxygen. For $\mathrm{HCl}$ oxidation, only $\mathrm{RuO}_{2}$ exhibits a clearly narrower tailing of the $\mathrm{HCl}$ response when comparing individual $\mathrm{HCl}$ and simultaneous $\mathrm{HCl}+\mathrm{O}_{2}$ pulses, indicating that only $\mathrm{RuO}_{2}$ is significantly active under TAP conditions (Fig. S10 $\dagger$ ). Thus, only $\mathrm{RuO}_{2}$ is considered for further comparative evaluation of $\mathrm{HBr}$ and $\mathrm{HCl}$ oxidation. A comparison of the $\mathrm{O}_{2}$ pulses after individual $\mathrm{O}_{2}$ and simultaneous $\mathrm{HBr}$ $+\mathrm{O}_{2}$ pulsing does not show a clear difference, because the integrated peak area is generally 10 times higher (Fig. S10†). This further indicates the presence of state-defining conditions, 
as the oxidic surface seems to be unchanged upon exposure to the large $\mathrm{O}_{2}$ pulses. ${ }^{15 d}$ In addition, the halogen surface coverage can be assumed to be very low (i.e. $<1 \%$ ), due to the small size of the HX gas pulses compared to the total surface area of the loaded catalysts under ultra-high vacuum (UHV) conditions. Thus, extensive surface or subsurface halogenation of the catalysts during the TAP experiment does not occur.

The product responses of $\mathrm{Br}_{2}, \mathrm{Cl}_{2}$, and $\mathrm{H}_{2} \mathrm{O}$ after simultaneous pulsing of $\mathrm{O}_{2}$ with either $\mathrm{HCl}$ or $\mathrm{HBr}$ are depicted in Fig. 4. When comparing the product responses, it is evident that $\mathrm{Cl}_{2}$ production is greater than $\mathrm{Br}_{2}$ production over $\mathrm{RuO}_{2}$ at the same temperature, which could be explained by the very low detection efficiency of the mass spectrometer for $\mathrm{Br}_{2}$ molecules, due to the lower bond strength of $\mathrm{Br}_{2}\left(193 \mathrm{~kJ} \mathrm{~mol}^{-1}\right)$ in comparison with $\mathrm{Cl}_{2}\left(243 \mathrm{~kJ} \mathrm{~mol}^{-1}\right)$, preventing a direct comparison of their signals. The bond strengths of $\mathrm{HBr}(363 \mathrm{~kJ}$ $\mathrm{mol}^{-1}$ ) and $\mathrm{HCl}\left(428 \mathrm{~kJ} \mathrm{~mol}^{-1}\right)$ are comparably high, so no effect on the detection efficiency is assumed. The direct calibration of the quadrupole mass spectrometer (QMS) using pulses of bromine and chlorine was considered, but was not conducted due to the unjustifiable damage expected to occur due to corrosion. However, comparing the signals due to water, which forms in stoichiometric amounts with either $\mathrm{Br}_{2}$ or $\mathrm{Cl}_{2}$, indicates that the rate of bromine formation must be higher than the rate of chlorine formation. The pulse response size of the water and bromine signals increases in the order: $\mathrm{IrO}_{2}<\mathrm{TiO}_{2}<$ $\mathrm{RuO}_{2}$, indicating the order of activity (Fig. 4, top row). The normalised signals show that the water response always reaches its peak maximum before the halogen response, suggesting that the halogen evolution is slower and can be considered the most energy-demanding step (Fig. 4, bottom row). However, the differences in mass between the water and halogen molecules could effect the observed shift of the peak response in the molecular diffusion regime, hampering in particular a comparison of the water and chlorine responses, due to their small difference in mass. In the case of $\mathrm{HBr}$ oxidation, the shift between the $\mathrm{HBr}$ and $\mathrm{Br}_{2}$ peak maxima can be safely interpreted as a measure of the activity of the catalysts. The shifts decrease in the order $\mathrm{IrO}_{2}(0.60 \mathrm{~s})>\mathrm{TiO}_{2}(0.43 \mathrm{~s})>\mathrm{RuO}_{2}(0.22 \mathrm{~s})$, which is the opposite order to that observed for product formation.

The faster bromine evolution observed over $\mathrm{TiO}_{2}$ compared to $\mathrm{IrO}_{2}$ is a crucial piece of experimental evidence that reaffirms the computational results. This proof could not be obtained through atmospheric pressure steady-state experiments because the apparent activity of both oxides in $\mathrm{HBr}$ oxidation was very similar. This is likely due to a compensation effect similar to that which occurs in the Deacon reaction on $\mathrm{RuO}_{2}$ at high coverage. ${ }^{5 a}$ The compensation that occurs between both materials is proposed to result from a breaking of the scaling relationships, as discussed recently. ${ }^{7}$ In the present work, the pulsing experiments in TAP allow the elementary steps of the reaction network to be decoupled. In this sense, it is possible to investigate only the desorption process, as it occurs under very low coverage and state-defining conditions, as explained above. Thus, in the absence of high bromine coverage we were able to observe the intrinsic differences in bromine evolution between $\mathrm{TiO}_{2}$ and $\mathrm{IrO}_{2}$, as postulated in ref. 7 .

In order to verify the reaction mechanism of $\mathrm{HBr}$ and $\mathrm{HCl}$ oxidation, pump-probe experiments were conducted, in which either the $\mathrm{HX}$ or the $\mathrm{O}_{2}$ pulse was delayed by a distinct time period (Fig. S11 and $\mathrm{S} 12 \dagger$ ). In the $\mathrm{O}_{2}$ (pump) and $\mathrm{HX}$ (probe) pulsing experiment, product formation can be observed after either pulse. The amount of product formed after the HX probe pulse is much larger, which is due to the available oxygen on the

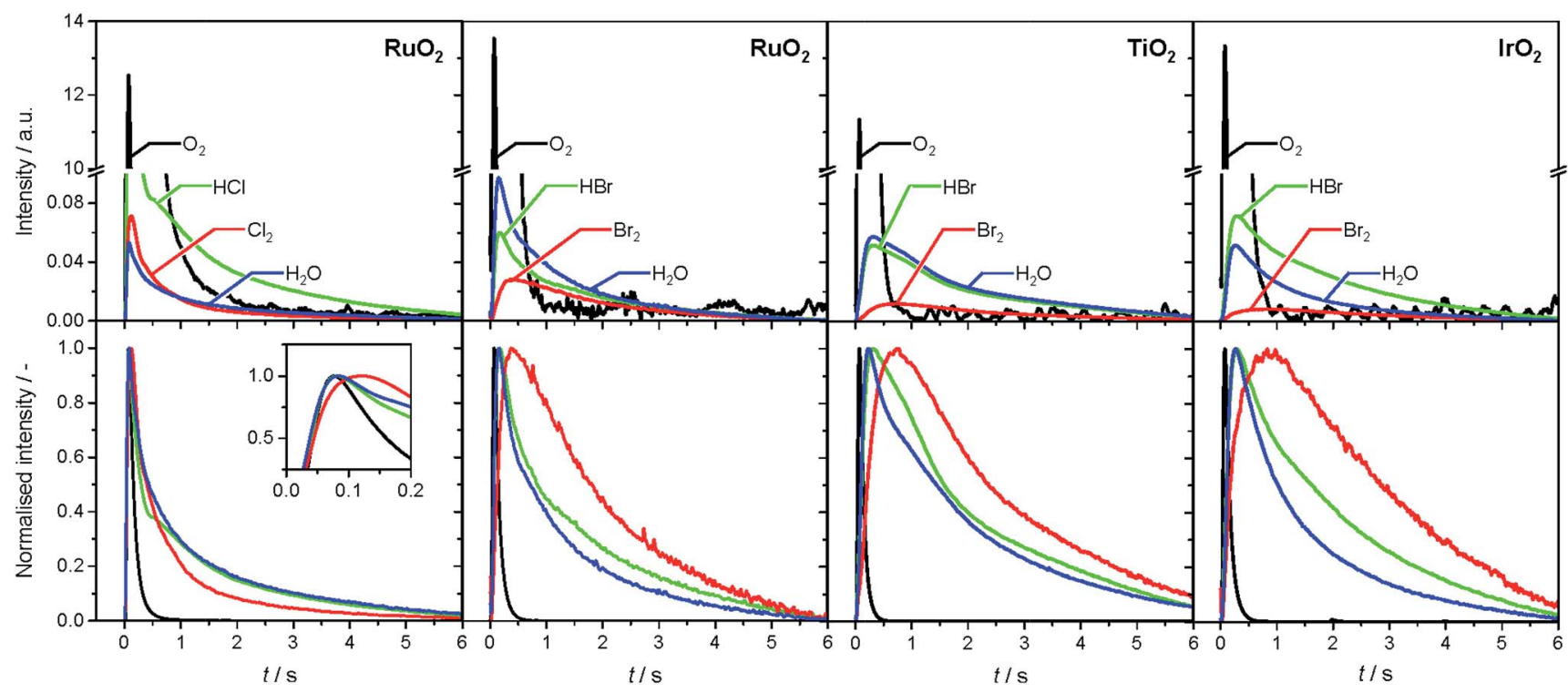

Fig. 4 Transient (top) and normalised transient (bottom) responses of reactants $\left(\mathrm{HCl}, \mathrm{HBr}, \mathrm{O}_{2}\right)$ and products $\left(\mathrm{Br}_{2}, \mathrm{Cl}_{2}, \mathrm{H}_{2} \mathrm{O}\right)$ at $623 \mathrm{~K}$ upon simultaneous pulsing of $\mathrm{HX}$ and $\mathrm{O}_{2}$ over rutile-type catalysts. The colour code applies to both the top and bottom rows. The break in the $y$-axis in the top plots enables a better visualization of the product responses: $\mathrm{Cl}_{2}, \mathrm{Br}_{2}$, and $\mathrm{H}_{2} \mathrm{O}$. The inset in the bottom left plot magnifies the region at the maxima of the normalised transient responses. 
surface following the pump pulse (Fig. S11†). This is analogous to the $\mathrm{HX}$ (pump) and $\mathrm{O}_{2}$ (probe) pulsing, in which the product formation after the HX pump pulse is also significant. The large amount of product formed after the $\mathrm{O}_{2}$ pulse can be related to oxygen-assisted product evolution (Fig. S12 $\dagger$ ), as described for $\mathrm{HCl}$ oxidation in recent studies. ${ }^{5 a}$

To further interpret our experiments and to complement earlier results, ${ }^{7}$ we computed the reaction profiles for $\mathrm{HBr}$ and $\mathrm{HCl}$ oxidation over halogenated rutile surfaces (Fig. S13†). For better comparison, the most important reaction steps are depicted in Fig. 5. The basic surface sites can strip a proton from HX, resulting in a surface hydroxyl and an adsorbed halide ion. Re-oxidation was identified as the key step in Deacon catalysis on $\mathrm{RuO}_{2}$ to close the cycle; this is the step where most differences appear between $\mathrm{RuO}_{2}$ and $\mathrm{TiO}_{2} \cdot \mathrm{O}_{2}$ adsorption on metallic surfaces like $\mathrm{RuO}_{2}$ and $\mathrm{IrO}_{2}$ is limited only by the number of free active sites available on the surface. ${ }^{19}$ On $\mathrm{TiO}_{2}$, oxygen chemistry is necessarily related to defect chemistry. ${ }^{7}$ In the present case, the defect chemistry originates from one of the reactants $(\mathrm{HBr})$, so it can be partially understood as auto-catalytic. This activity is only possible for $\mathrm{HBr}$, as the $\mathrm{Cl}(3 \mathrm{p})$ levels in $\mathrm{Cl}$ are far too low in energy compared to the $\mathrm{Br}(4 \mathrm{p})$ levels in $\mathrm{Br}$ (resulting in a stronger adsorption for $\mathrm{Cl}$ ), and thus the energy required to eliminate $\mathrm{Cl}_{2}$ from the surface is far too high for the reaction to occur in the temperature window for $\mathrm{TiO}_{2}$ activity. ${ }^{7}$ In addition, for HX oxidation to take place, sites capable of both acid-base and redox interactions are required. ${ }^{7}$ Metal oxides with metallic properties exhibit both of these characteristics to a reasonable degree, but the redox properties are more subtle for semiconductors, in which defect levels play the leading role. In view of the product evolution, $\mathrm{Cl}_{2}$ recombination is more energy-demanding than $\mathrm{Br}_{2}$ recombination, with the recombination energy of the latter over different surfaces increasing in the following order: $\mathrm{RuO}_{2}(\mathrm{Br})(1.9 \mathrm{eV})<\mathrm{TiO}_{2}(\mathrm{Br})(2.44 \mathrm{eV})<$ $\mathrm{IrO}_{2}(\mathrm{Br})(3.05 \mathrm{eV}) \cdot \boldsymbol{\Phi}{ }^{, 20}$ This coincides with the product evolution observed in the simultaneous pulsing experiments. The recombination of two halogen atoms on the surface is the most energy-demanding reaction step in all investigated systems. Water evolution is less energy-demanding by more than $1 \mathrm{eV}$ (Fig. 5). For the latter, the hydroxyl groups can recombine over the surface, generating an adsorbed water molecule that can then leave the surface. These water-related steps have very similar mechanisms on all of the surfaces.

\section{Impact of the halogen surface coverage}

The halogen coverage on the catalysts was determined by operando PGAA under real-life conditions for $\mathrm{RuO}_{2}$ and $\mathrm{TiO}_{2}$. An investigation of $\mathrm{IrO}_{2}$ was unfortunately not possible, because the neutron excitation and radioactive decay of Ir leads to the emission of very intense gamma radiation that rapidly saturates the detector, and the high baseline created by the Ir matrix overshadows the Br signal. ${ }^{21}$ Thus, the comparison focused on $\mathrm{TiO}_{2}$ and $\mathrm{RuO}_{2}$ at variable $\mathrm{O}_{2}: \mathrm{HX}$ feed ratios and temperatures (Fig. 6), where the $\mathrm{HCl}$ and $\mathrm{HBr}$ conversion reached maximum values of $29 \%$ and $84 \%$, respectively.

As shown in Fig. 6a, $\mathrm{TiO}_{2}$ exhibits halogen coverages of 0.57 and 0.48 for $\mathrm{Br}$ and $\mathrm{Cl}$ respectively, at $\mathrm{O}_{2}: \mathrm{HX}=0$. With increasing oxygen partial pressure, these values decrease to 0.4 $(\mathrm{Br})$ and $0.36(\mathrm{Cl})$. The $\mathrm{Cl}$ coverage on $\mathrm{RuO}_{2}$ is close to 1 at $\mathrm{O}_{2}: \mathrm{HCl}=0$ and reaches 0.86 at $\mathrm{O}_{2}: \mathrm{HCl}=9$, which is in line with recent studies. ${ }^{5}$ However, in agreement with our HRTEM and DFT results, $\mathrm{RuO}_{2}$ exhibits subsurface bromination when varying the $\mathrm{O}_{2}$ : $\mathrm{HBr}$ ratio from 0 to 9 , reaching a degree of bromination that exceeds the theoretical full surface coverage by $300 \%$ (Fig. $\mathrm{S} 14 \dagger$ ). Therefore, the tests on $\mathrm{RuO}_{2}$ in $\mathrm{HBr}$ were conducted under slightly different conditions, with the $\mathrm{O}_{2}: \mathrm{HBr}$ ratio decreasing from 9 to 1 , whereby the $\mathrm{Br}$ coverage increased from 0.65 to 1.48 (Fig. 6a). The dependence of the halogen coverage on the variation of the bed temperature, as indicated in the respective plots, is very similar to the dependence of the halogen coverage on the oxygen partial pressure (Fig. 6b and $\mathrm{S} 15 \dagger)$. On increasing the temperature, the halogen coverage on
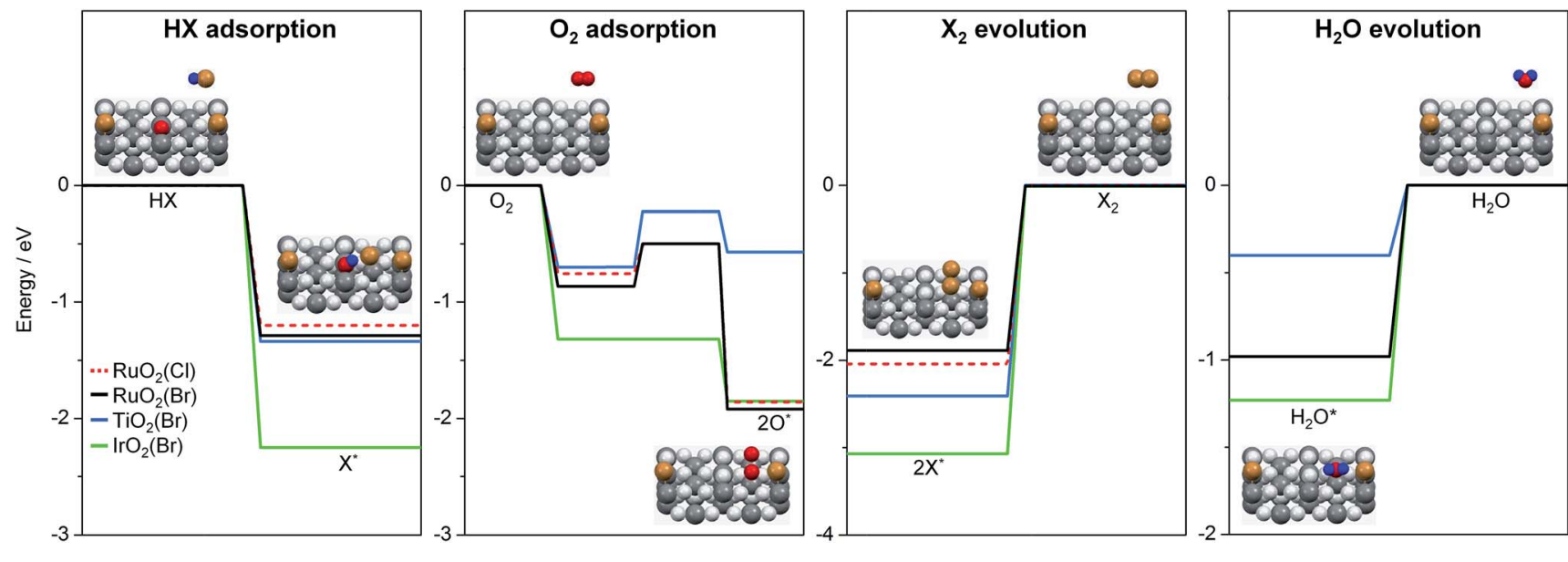

Fig. 5 Key steps of reactant adsorption and product evolution steps for $\mathrm{HBr}$ (solid lines) and $\mathrm{HCl}$ (dashed line) oxidation on halogenated rutiletype surfaces. The $\mathrm{H}_{2} \mathrm{O}$ evolution steps over $\mathrm{RuO}_{2}(\mathrm{X})$ for $\mathrm{HBr}$ (black) and $\mathrm{HCl}$ (red) oxidation overlap. The full reaction profile is shown in Fig. S13. $\dagger$ The insets illustrate the reaction steps on a rutile surface. Colour code: metal atoms (dark grey), $\mathrm{Br}$ (brown), $\mathrm{H}$ (blue), and O (light grey and red). $\mathrm{O}$ atoms are coloured in red if they participate in the reaction. 

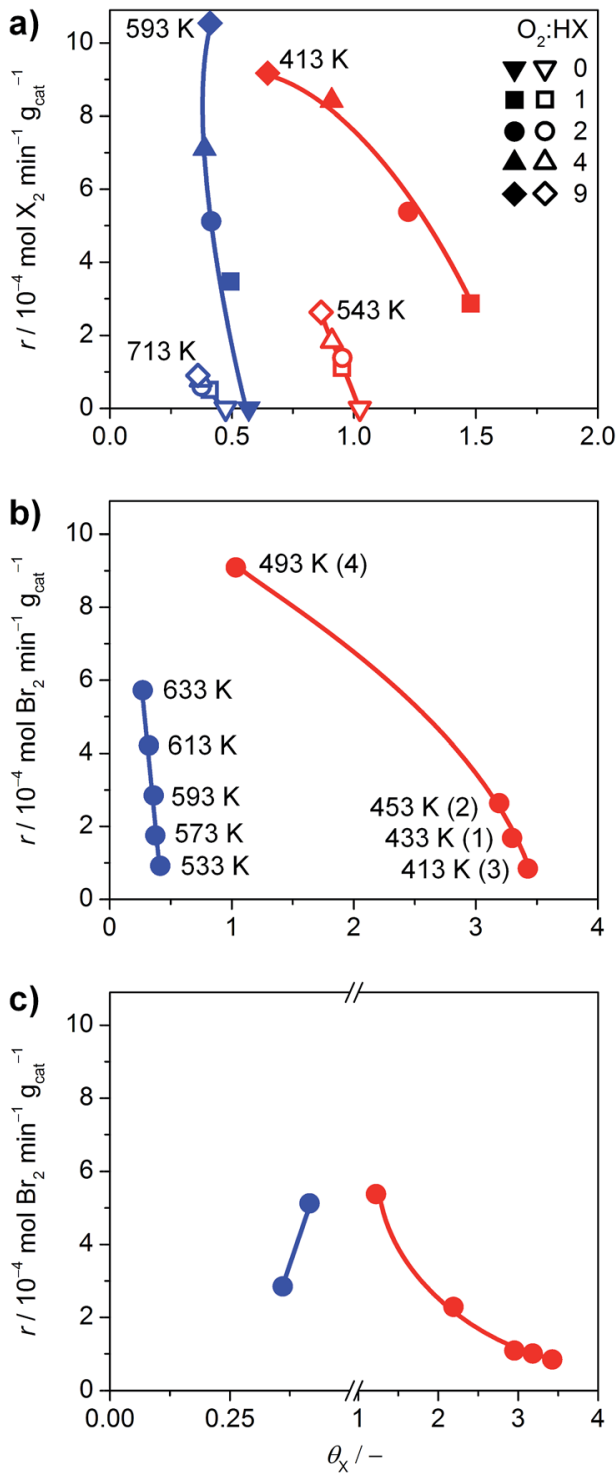

Fig. 6 (a) Rate of halogen formation of $\mathrm{HBr}$ (solid symbols) and $\mathrm{HCl}$ (open symbols) oxidation as a function of the halogen coverage over $\mathrm{TiO}_{2}$ (blue) and $\mathrm{RuO}_{2}$ (red), showing the dependence on the $\mathrm{O}_{2}: \mathrm{HX}$ feed ratio at constant temperature. The $\mathrm{O}_{2}: \mathrm{HX}$ ratio was increased from 0 to 9, except for the $\mathrm{HBr}$ oxidation over $\mathrm{RuO}_{2}$, where the order was inverted from 9 to 1. (b) Dependence of the rate on the catalyst bed temperature at $\mathrm{O}_{2}: \mathrm{HBr}=2$. The temperature for $\mathrm{TiO}_{2}$ was increased from $533 \mathrm{~K}$ to $633 \mathrm{~K}$. The order of measurements for $\mathrm{RuO}_{2}$ is indicated by the numbers in parentheses. (c) Rate of bromine formation versus the bromine coverage. The data points $\left(\mathrm{O}_{2}: \mathrm{HBr}=2,593 \mathrm{~K}\right.$ for $\mathrm{TiO}_{2}$, and $413 \mathrm{~K}$ for $\mathrm{RuO}_{2}$ ) were taken from the measurements shown in ( $a$ and $b$ ), and Fig. S14. $\uparrow$ Coverages exceeding unity indicate the occurrence of subsurface halogenation.

$\mathrm{TiO}_{2}$ drops from $0.41(\mathrm{Br})$ and $0.54(\mathrm{Cl})$ to $0.27(\mathrm{Br})$ and $0.38(\mathrm{Cl})$, respectively. The halogen coverages on $\mathrm{TiO}_{2}$ are significantly lower compared to $\mathrm{RuO}_{2}$, which is in agreement with the $a b$ initio thermodynamics. In Fig. 6c, data points from the different experiments are combined to show the effect of bromine coverage on the rate under the same reaction conditions. The bromine coverage on $\mathrm{TiO}_{2}$ is so low that a slight increase in surface bromine content leads to a higher activity. On the other hand, the bromine coverage on $\mathrm{RuO}_{2}$ is above the theoretical surface coverage, and further increases are detrimental to the activity of $\mathrm{RuO}_{2}$ in $\mathrm{HBr}$ oxidation (Fig. 6c). Thus, an optimal halogen coverage between the observed values for $\mathrm{TiO}_{2}$ and $\mathrm{RuO}_{2}$, at which the bromine formation rate would be maximal is likely to exist.

The impact of product inhibition was investigated for $\mathrm{TiO}_{2}$ by adding bromine to the gas feed (Fig. 7a). The addition of $4 \mathrm{vol} \% \mathrm{Br}_{2}$ causes a distinct decrease in the bromine formation rate of $55 \%$. However, the bromine coverage stabilises at 0.43 after increasing the bromine feed to $2 \mathrm{vol} \%$. This indicates that there is no significant bromination of the catalysts through the addition of bromine gas, which is in agreement with the endothermic adsorption of $\mathrm{Br}_{2}$ on clean $\mathrm{TiO}_{2}$ as calculated by DFT $\left(0.69 \mathrm{eV}\right.$ with respect to $\left.\frac{1}{2} \mathrm{Br}_{2}\right)$; a bifunctional adsorption as proposed by $\mathrm{Li}$ and Metiu ${ }^{20}$ does not improve the adsorption energy. Recent studies highlighted that the gas-phase thermodynamic equilibrium of $\mathrm{HBr}$ oxidation is shifted far to the side of the products. ${ }^{6 d}$ Thus, the decreased activity is not linked to a shift in the thermodynamic equilibrium, but is due to the reaction kinetics. The determination of the apparent reaction order gives a value of -0.44 for the impact of bromine on the reaction rate (Fig. $7 \mathrm{~b}$ ). This value is close to the theoretical apparent order of -0.5 , which describes the dissociative adsorption of bromine on the active site. Hence, it seems plausible that a competitive adsorption between $\mathrm{HBr}$ and $\mathrm{Br}_{2}$
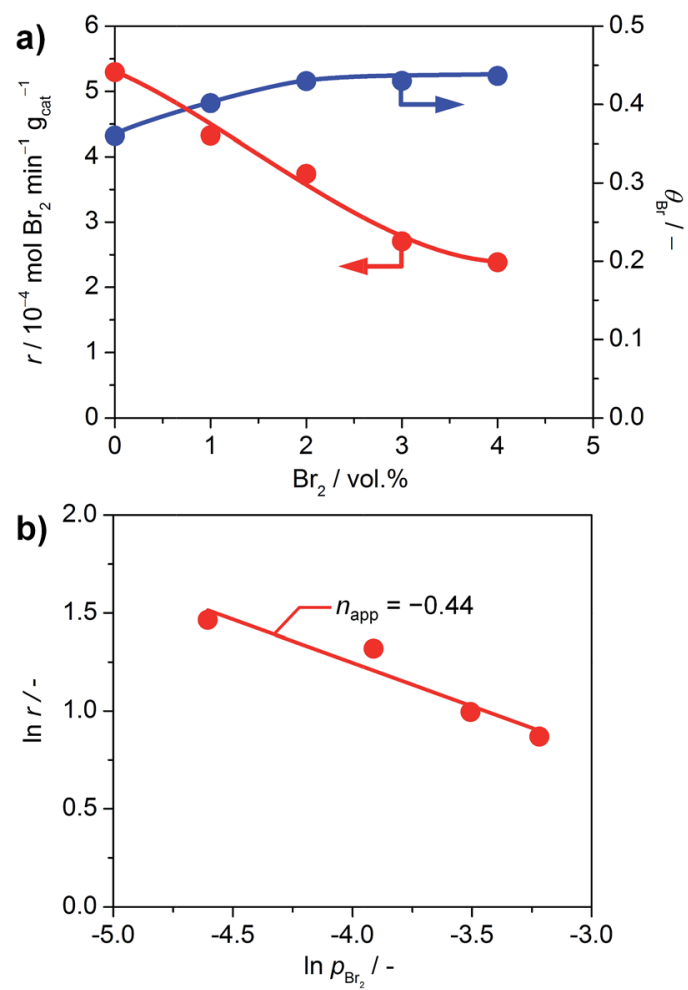

Fig. 7 (a) Rate of bromine formation (red) and bromine surface coverage (blue) versus the volumetric feed of bromine over $\mathrm{TiO}_{2}$ at $593 \mathrm{~K}$ and $\mathrm{O}_{2}: \mathrm{HBr}=2$. (b) Rate of bromine formation versus partial pressure of bromine. 
occurs on the small number of active sites of $\mathrm{TiO}_{2}$ and likely depends on the defect states left on its surface, originating from doping by the small amount of $\mathrm{Br}$ taken up by the surface. As a comparison, the inhibition effect of $\mathrm{Cl}_{2}$ on $\mathrm{RuO}_{2}$ in the Deacon reaction is $-1.00 .^{5 a}$ The larger inhibitions induced for $\mathrm{RuO}_{2}$ catalysts are due to the fact that site competition is favoured on metallic substrates, compared to semiconductors like $\mathrm{TiO}_{2}$. The ultimate reason for this is that once doped, the Ti centres are no longer chemically equivalent to each other, and thus they discriminate between the adsorption of electron-rich and electron-poor fragments. In comparison, the conduction band in metals screens out these effects, and it is not possible to differentiate the chemical nature of the cations.

\section{Halogen chemistry on rutile surfaces}

With all the data described in the previous sections, a generalised picture of the chemistry of halogens on rutile catalysts emerges. Although the chemical nature of $\mathrm{HCl}$ and $\mathrm{HBr}$ might appear to be virtually identical at a first glance, their interactions with the set of potential catalysts are markedly different. Initially, the surface basicity and the acidic character of HX leads to an exothermic adsorption pattern for all combinations. But, depending on the particular oxide/hydrogen halide pair, the adsorption can lead to: (i) a minor fraction of oxygen lattice replacement $\left(\mathrm{TiO}_{2} / \mathrm{HBr}\right)$, (ii) a medium level of oxygen lattice replacement and a large surface coverage $\left(\mathrm{RuO}_{2} / \mathrm{HCl}\right)$, or (iii) an extensive surface modification with concomitant subsurface occupation and the growth of a second phase on the surface $\left(\mathrm{RuO}_{2} / \mathrm{HBr}\right)$. The factors controlling these differences are related to: (i) the nature of the oxides and (ii) their limited ability to store extra electrons in defect states $\left(\mathrm{TiO}_{2}\right)$, while for the metallic oxides $\left(\mathrm{RuO}_{2}\right.$ and $\left.\mathrm{IrO}_{2}\right)$, the extent of halide replacement is mostly governed by the relative energies of the $\mathrm{M}-\mathrm{O}$ and $\mathrm{M}-\mathrm{X}$ bonds.

The activity of the rutile is then completely governed by the halide content in the material; to quote Paracelsus, the dose makes the poison. Thus, the mechanism might range from only involving surface positions (Langmuir-Hinshelwood-type mechanism) as for $\mathrm{HBr}$ on $\mathrm{TiO}_{2}$, through a continuum that involves the activation and/or replacement of surface lattice oxygen atoms (i.e. closer to a Mars-van-Krevelen-type mechanism). The active catalyst must then be obtained through control of the oxygen pressure in the gas-phase, which can limit the halide content to only surface positions, thus rendering the catalyst active. The single exception to this behaviour is the semiconductor material $\mathrm{TiO}_{2}$. For $\mathrm{TiO}_{2}$, the self-doping occurring as a result of replacement of the surface oxygen atoms by halide is self-limited, due to the energy cost of accumulating electrons in surface and subsurface states. ${ }^{22}$ The activity is then linked to the presence of forbidden energy areas, from which it is possible to add/extract electrons, and how effective the alignment of the energy levels is.

\section{Conclusions}

We have investigated $\mathrm{HBr}$ and $\mathrm{HCl}$ oxidation on rutile $\mathrm{RuO}_{2}$, $\mathrm{IrO}_{2}$, and $\mathrm{TiO}_{2}$ catalysts by applying an integrated approach consisting of advanced methods to analyse and compare their surface chemistry. We found that the structural stability of the HX oxidation catalysts depends on the interactions of the hydrogen halide molecules with the catalyst surface. The combined HRTEM, DFT, and TAP studies reveal that the amorphisation of the $\mathrm{RuO}_{2}$ particle surface after treatment with $\mathrm{HBr}$ is due to structural distortion of the clean surface geometry after extensive bromination. Notice, however, that extensive bromination and thus surface amorphisation also occurred in $\mathrm{HBr}$ oxidation. The impact of $\mathrm{HCl}$ is much more limited, leading to less pronounced distortion as a result of the comparably unfavourable energetics of oxygen substitution, restricting $\mathrm{Cl}$ replacement to the surface. The computed bromine substitution into the $\mathrm{TiO}_{2}$ lattice is endothermic, suggesting only limited potential for bromination. The TAP experiments support these results, indicating a stronger interaction of rutile-type materials with $\mathrm{HBr}$ than with $\mathrm{HCl}$. Further pulsing experiments in TAP indicate that halogen evolution can be considered to be the most energy-demanding step, with the activity of the catalysts for $\mathrm{HBr}$ oxidation increasing in the following order: $\mathrm{IrO}_{2}<\mathrm{TiO}_{2}<\mathrm{RuO}_{2}$. This coincides with the computational results. Both $\mathrm{HBr}$ and $\mathrm{HCl}$ oxidation reactions follow a Langmuir-Hinshelwood-type mechanism on surfaces with a low to moderate degree of halogenation, as confirmed through pump-probe experiments. The halogen uptake is the key descriptor that links stability and activity of the catalytic systems. On $\mathrm{RuO}_{2}$, the steady-state surface halogen coverage reaches $86-100 \%$ for chlorine and $75-300 \%$ for bromine, proving that subsurface bromination occurs, agreeing with the HRTEM and DFT studies. A decrease in the halogen coverage on $\mathrm{RuO}_{2}$ can be induced by increasing the operation temperature and elevating the $\mathrm{O}_{2}$ : $\mathrm{HX}$ feed ratio. Still, our tools cannot describe in detail the mechanism for surface/subsurface bromination. It is possible that some degree of subsurface $\mathrm{Br}$ uptake takes place early in the reaction process, before the surface is completely saturated with bromine. This will affect the catalyst activity in the long term, even at higher temperatures. In contrast, the halogen coverage of $\mathrm{TiO}_{2}$ is limited to $30-50 \%$ as a result of its self-doping mechanism with bromine. An increase in the temperature and the $\mathrm{O}_{2}: \mathrm{HX}$ feed ratio induces higher activity, but does not significantly affect the halogen coverage on $\mathrm{TiO}_{2}$. The addition of $\mathrm{Br}_{2}$ to the gas feed over $\mathrm{TiO}_{2}$ does not affect the bromine coverage, but inhibits the reaction at an apparent order of -0.44 , indicating a competitive adsorption of $\mathrm{Br}_{2}$ and $\mathrm{HBr}$ on the active sites. As a result of this study, we consider it highly desirable to combine the exceptional low-temperature activity of $\mathrm{RuO}_{2}$ with the stability of $\mathrm{TiO}_{2}$ against extensive surface halogenation by designing new $\mathrm{Ru}-\mathrm{Ti}$ mixed oxide catalysts for $\mathrm{HBr}$ oxidation with an optimal balance between activity and stability.

\section{Acknowledgements}

We thank Dr Frank Krumeich and ScopeM, the Scientific Center for Optical and Electron Microscopy of ETH Zurich, for microscopic studies and the BSC-RES for providing computational resources. The Swiss National Science Foundation (SNF project 
number 200021-156107), the European Union's 7th Framework Programme (NMI3-II grant number 283883), the ICIQ Foundation, and the MINECO (grant number CTQ2012-33826/BQU) are acknowledged for financial support.

\section{Notes and references}

\$ The ab initio thermodynamics should be interpreted with caution as a number of approximations (i.e. configurational entropies are missing) have been implicitly included, and thus this model only serves for qualitative purposes.

$\S$ The preference for bromination can be seen from the fact that the transition between the $2 \mathrm{~A}$ and $4 \mathrm{~B}$ configurations occurs at lower pressures than for $\mathrm{Cl}$.

If For $\mathrm{TiO}_{2}$, two different configurations were tested and the most stable one is taken into account.

1 (a) J. Pérez-Ramírez, C. Mondelli, T. Schmidt, O. F.-K. Schlüter, A. Wolf, L. Mleczko and T. Dreier, Energy Environ. Sci., 2011, 4, 4786; (b) H. Over, Chem. Rev., 2012, 112, 3356.

2 (a) A. Fujishima, X. T. Zhang and D. A. Tryk, Surf. Sci. Rep., 2008, 63, 515; (b) Y. Lee, J. Suntivich, K. J. May, E. E. Perry and Y. Shao-Horn, J. Phys. Chem. Lett., 2012, 3, 399.

3 (a) K. Seki, Catal. Surv. Asia, 2010, 14, 168; (b) A. P. Amrute, C. Mondelli, T. Schmidt, R. Hauert and J. Pérez-Ramírez, ChemCatChem, 2013, 5, 748.

4 (a) N. López, J. Gómez-Segura, R. P. Marín and J. PérezRamírez, J. Catal., 2008, 255, 29; (b) D. Crihan, M. Knapp, S. Zweidinger, E. Lundgren, C. J. Weststrate, J. N. Andersen, A. P. Seitsonen and H. Over, Angew. Chem., Int. Ed., 2008, 47, 2131; (c) A. P. Seitsonen and H. Over, J. Phys. Chem. C, 2010, 114, 22624; (d) M. G. Hevia, A. P. Amrute, T. Schmidt and J. Pérez-Ramírez, J. Catal., 2010, 276, 141.

5 (a) D. Teschner, R. Farra, L. Yao, R. Schlögl, H. Soerijanto, R. Schomäcker, T. Schmidt, L. Szentmiklósi, A. P. Amrute, C. Mondelli, J. Pérez-Ramírez, G. Novell-Leruth and N. López, J. Catal., 2012, 285, 273; (b) D. Teschner, G. Novell-Leruth, R. Farra, A. Knop-Gericke, R. Schlögl, L. Szentmiklósi, M. G. Hevia, H. Soerijanto, R. Schomäcker, J. Pérez-Ramírez and N. López, Nat. Chem., 2012, 4, 739.

6 (a) E. McFarland, Science, 2012, 338, 340; (b) A. Toftelund, I. C. Man, H. A. Hansen, F. Abild-Pedersen, T. Bligaard, J. Rossmeisl and F. Studt, ChemCatChem, 2012, 4, 1856; (c) K. Ding, H. Metiu and G. D. Stucky, ChemCatChem, 2013,
5, 1906; (d) M. Moser, L. Rodríguez-García, A. P. Amrute and J. Pérez-Ramírez, ChemCatChem, 2013, 5, 3520.

7 M. Moser, I. Czekaj, N. López and J. Pérez-Ramírez, Angew. Chem., Int. Ed., 2014, 53, 8628.

8 (a) G. Kresse and J. Furthmüller, Comput. Mater. Sci., 1996, 6, 15; (b) G. Kresse and J. Furthmüller, Phys. Rev. B: Condens. Matter Mater. Phys., 1996, 54, 11169.

9 H. Monkhorst and J. Pack, Phys. Rev. B: Solid State, 1976, 13, 5188.

10 J. P. Perdew, K. Burke and M. Ernzerhof, Phys. Rev. Lett., 1996, 77, 3865.

11 (a) M. Cococcioni and S. de Gironcoli, Phys. Rev. B: Condens. Matter Mater. Phys., 2005, 71(035105), 1; (b) H. J. Kulik, M. Cococcioni, D. A. Scherlis and N. Marzari, Phys. Rev. Lett., 2006, 97(103001), 1.

12 P. E. Blöchl, Phys. Rev. B: Condens. Matter Mater. Phys., 1994, 50, 17953.

13 G. Henkelman, B. P. Uberuaga and H. J. Jónsson, Chem. Phys., 2000, 113, 9901.

14 NIST, http://webbook.nist.gov/chemistry, 8th July 2015.

15 (a) J. T. Gleaves, G. S. Yablonsky, P. Phanawadee and Y. Schuurman, Appl. Catal., A, 1997, 160, 55; (b) S. O. Shekhtman, G. S. Yablonsky, S. Chen and J. T. Gleaves, Chem. Eng. Sci., 1999, 54, 4371; (c) J. PérezRamírez and E. V. Kondratenko, Catal. Today, 2007, 121, 160; (d) J. T. Gleaves, G. S. Yablonsky, X. Zheng, R. Fushimi and P. L. Mills, J. Mol. Catal. A: Chem., 2010, 315, 108.

16 R. Farra, M. Eichelbaum, R. Schlögl, L. Szentmiklósi, T. Schmidt, A. P. Amrute, C. Mondelli, J. Pérez-Ramírez and D. Teschner, J. Catal., 2013, 297, 119.

17 G. Novell-Leruth, G. Carchini and N. López, J. Chem. Phys., 2013, 138, 194706.

18 A. P. Amrute, C. Mondelli, M. A. G. Hevia and J. PérezRamírez, J. Phys. Chem. C, 2011, 115, 1056.

19 M. Moser, C. Mondelli, A. P. Amrute, A. Tazawa, D. Teschner, M. E. Schuster, A. Klein-Hoffman, N. López, T. Schmidt and J. Pérez-Ramírez, ACS Catal., 2013, 3, 2813.

20 B. Li and H. Metiu, J. Phys. Chem. C, 2012, 116, 4137.

21 Z. Révay and T. Belgya, Principles of the PGAA method in Handbook of Prompt Gamma Activation Analysis with Neutron Beams, ed. G. L. Molnár, Kluwer, 2004, pp. 23-28, sections 3.2-3.3.

22 Z. Zhang and J. T. Yates, Chem. Rev., 2012, 112, 5520. 